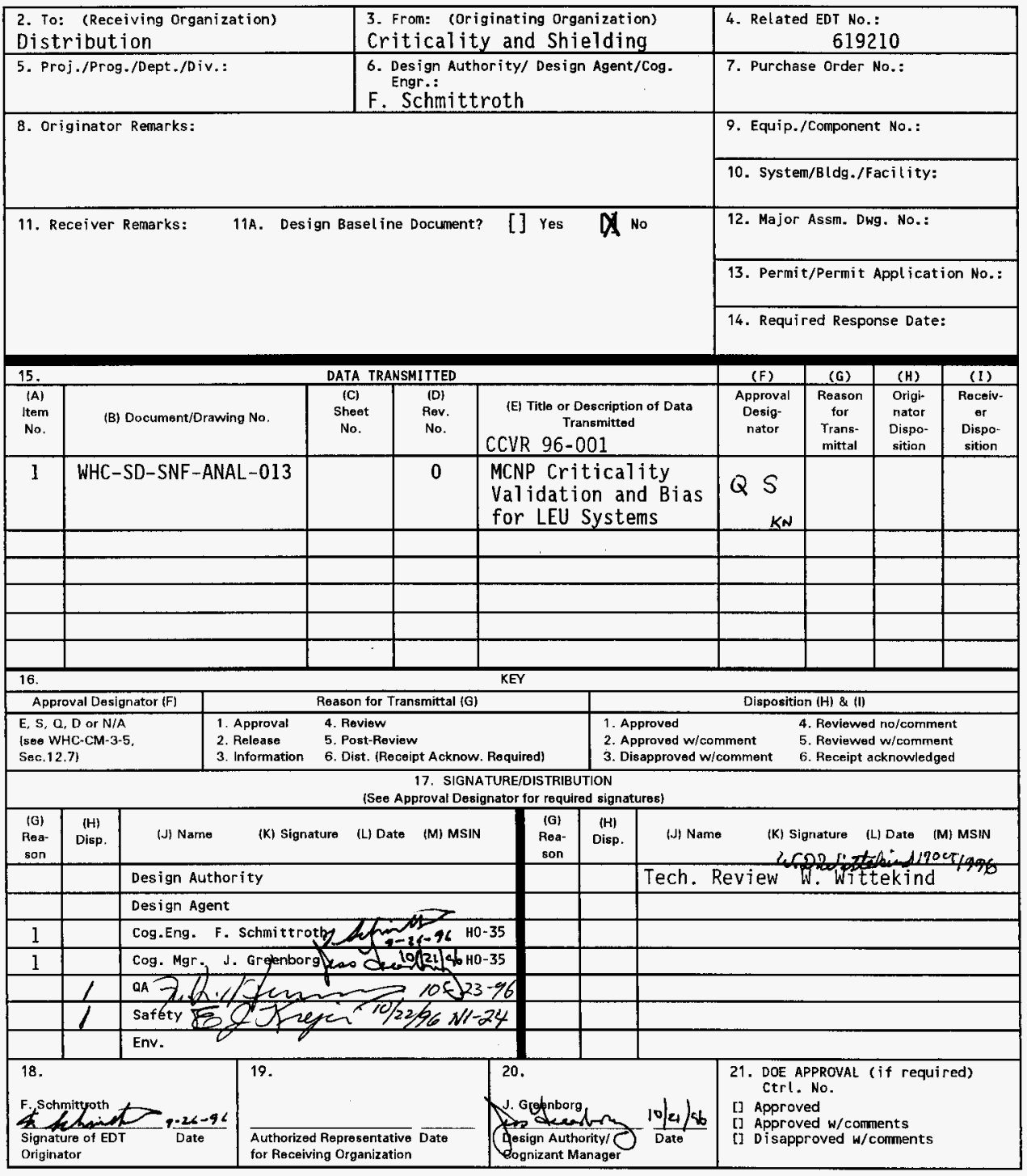




\section{MCNP Criticality Validation and Bias for LEU System}

\section{F. Schmittroth}

Westinghouse Hanford Company, Richland, WA 99352

U.S. Department of Energy Contract DE-AC06-87RL10930

$\begin{array}{llll}\text { EDT/ECN: } & 619210 & \text { UC: } 510 \\ \text { Org Code: } & 8 M 730 & \text { Charge Code: } & \text { LG070 } \\ \text { B\&R Code: } & \text { EW3135040 } & \text { Total Pages: } 19\end{array}$

Key Words: Criticality, MCNP, Validation, Low Enriched Uranium

Abstract: The bias in MCP calculations was evaluated for low enriched uranium (LEU) systems typical of $\mathrm{N}$ reactor fuel. A formula that includes the bias and its uncertainties is given to ensure that LEU systems are safely subcritical.

TRADEMARK DISCLAIMER. Reference herein to any specific commercial proctuct, process, or service by trade name, trademark, manufacturer, or otherwise, does not necessarily constitute or imply its endorsement, recommendation, or favoring by the United States Government or any agency thereof or its contractors or subcontractors.

Printed in the United States of America. To obtain copies of this document, contact: WHC/BCS Document Control Services, P.O. Box 1970, Maílstop H6-08, Rich Land wh 00252 Phone (509) 372-2420; Fax (509) 376-4989.
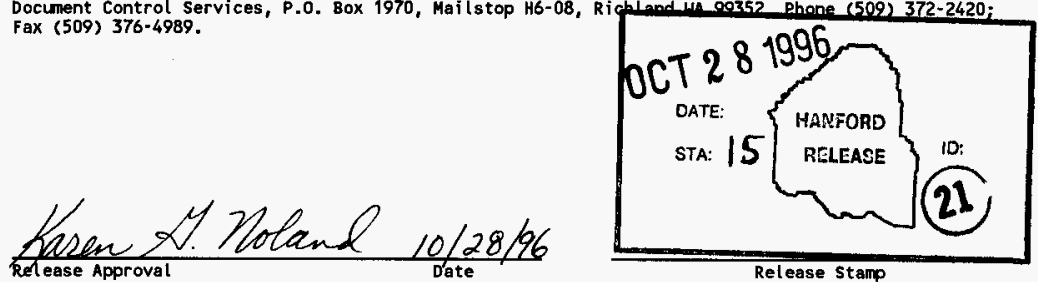

Release Stamp

\section{Approved for Public Release}


WHC-SD-SNF-ANAL-013 Rev. 0

CCVR 96-001

Computer Code Validation Report 96-001

Title: MCNP Criticality Validation and Bias for LEU Systems

Prepared by:

F. Schmittroth and R.H. Ruben

Engineers, Criticality and Shielding

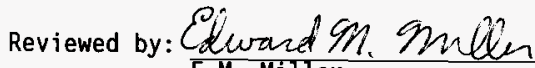
E.M. Miller Engineer, Criticality and Shielding

Reviewed by: 2 arrow $\alpha$. 2ittekind

W. D. Wittekind

Engineer, Criticality and Shielding

Approved by:

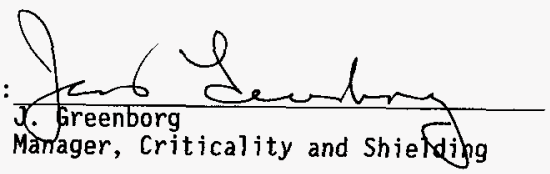

Date: $10 / 16 / 96$

Date: October 16,1996

Date: 17 october 1996

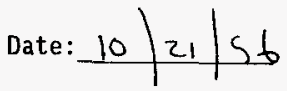

1 


\section{CONTENTS}

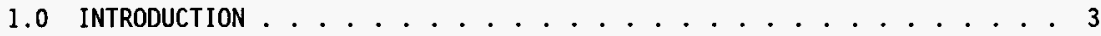

2.0 EXPERIMENTAL RESULTS .................... 3

$2.1 \mathrm{UO}_{3}-\mathrm{H}_{2} \mathrm{O}$ Solution Measurements ............ 3

2.2 MKIA Lattice Experiment ............ . . 3

2.3 Benchmark experiment for $2.35 \%$ enriched lattice . . . . . 7

3.0 STATISTICAL ANALYSIS . . . . . . . . . . . . . . . 9

4.0 RESULTS AND RECOMMENDATIONS ................. 12

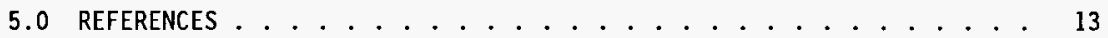

\section{LIST OF FIGURES}

Figure 1. MCNP Calculated $\mathrm{k}_{\text {inf }}$ for Homogeneous $\mathrm{UO}_{3}-\mathrm{H}_{2} \mathrm{O}$ System.

HW-70310 Experiments Modeled ........... 4

Figure 2. MCNP Calculations of $k_{\text {eff }}$ for MKIA lattices Compared to Experimental Results from (Brown et a1. 1965) . . . . . 6

Figure 3. Ratio of MCNP Calculations to Experimental Values for Low-Enriched Systems ............ 10

\section{LIST OF TABLES}

Table 1. MCNP Calculations (Wittekind 1992) and Experimental Results (Neeley and Handler 1961) for Homogeneous $\mathrm{UO}_{3}-\mathrm{H}_{2} \mathrm{O}$ Systems. . . 5

Table 2. MCNP Calculations for Benchmark LEU-COMP-THERM-001 as Reported in Briggs et al. (1992) .............. 8

Table 3. Statistical MCNP Bias Results for Three Experiments and the pooled Data ..................... . . . . . . . . . 
WHC-SD-SNF-ANAL-013 Rev. 0

MCNP CRITICALITY VALIDATION AND BIAS FOR LEU SYSTEMS

\subsection{INTRODUCTION}

An evaluation of K Basin criticality by Wittekind (1992) includes a validation of the Monte Carlo code MCNP (Carter 1991) used in the study. Comparisons were made to several criticality experiments and to other criticality codes, specifically the WIMS (versions D and E) code (WIMS 1992). The comparisons provide good support for the use of MCNP in low-enriched uranium (LEU) systems typical of $\mathrm{N}$ Reactor fuel in the $\mathrm{K}$ basins.

The purpose of this report is to reexamine the experimental support for the validation and to determine a calculational bias to be used in further criticality evaluations. New validation calculations are not undertaken.

Two experiments reported by Wittekind are considered here: an early report on $\mathrm{UO}_{3}-\mathrm{H}_{2} \mathrm{O}$ solutions (Neeley and Handler 1961), and a lattice experiment using actual MKIA $N$ reactor fuel elements (Brown et al. 1965). A third experiment performed by Douglas United Nuclear in the $105 \mathrm{~N}$ Fuel Storage Basin (Neilson and Toffer 1975) reported $k_{\text {eff }}$ values that were often well below the MCNP results. Finally results from a benchmark experiment using $2.35 \%$ enriched fuel (Briggs et al. 1992) are included.

The experimental results are considered in the next section, and a statistical analysis is performed in Section 3.0. Results and recommendations are given in Section 4.0.

\subsection{EXPERIMENTAL RESULTS}

\section{$2.1 \mathrm{UO}_{3}-\mathrm{H}_{2} \mathrm{O}$ Solution Measurements}

The homogeneous wet uranium $\mathrm{UO}_{3}-\mathrm{H}_{2} \mathrm{O}$ solution experiments consisted of 12 measured values for three different enrichments and a range of hydrogen to uranium $(H / U)$ ratios from 3.73 to 7.45 . The results were reported as $k_{\infty}$ and are compared by Wittekind to the MCNP results in Figure 1 which is taken directly from Wittekind's report (Wittekind 1992). The comparisons show that MCNP values are in good agreement with the experimental results and correctly follow the variations in $k_{\infty}$ both as a function of enrichment and the $\mathrm{H} / \mathrm{U}$ ratio. Table 1 gives numerical values for both the experiment and MCNP. A11 values used here for this experiment were taken directly from Wittekind (1992); the experimental report (Neeley and Handler 1961) was not reviewed. 
HHC-SD-SNF-ANAL-013, ReV. O

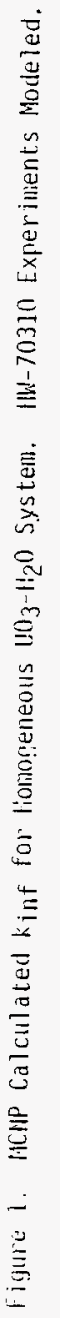

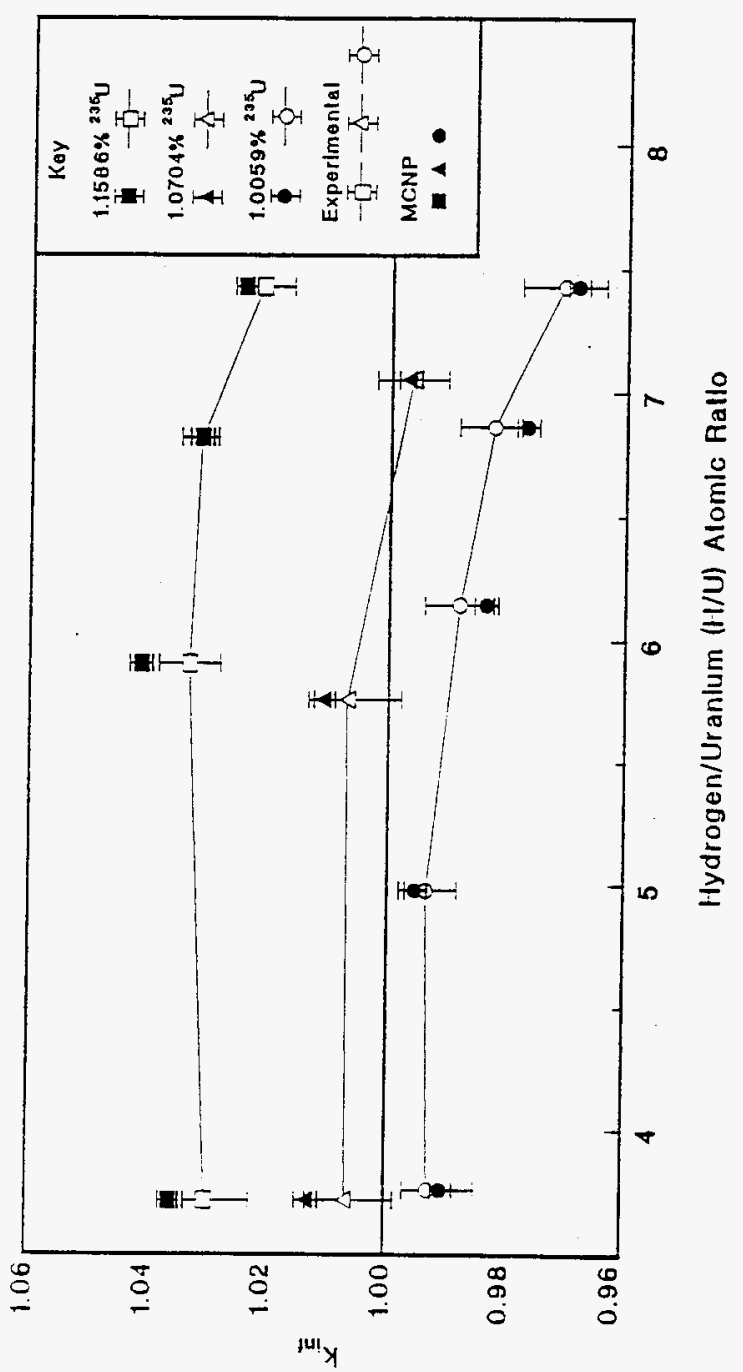


Table 1. MCNP Calculations (Wittekind 1992) and Experimental Results (Neeley and Handler 1961) for Homogeneous $\mathrm{UO}_{3}-\mathrm{H}_{2} \mathrm{O}$ Systems. The values are taken directly from Wittekind (1992).

$\begin{array}{ccccc}\text { Enrichment } & H / U & \text { MCNP } & \text { Experiment } & \text { Exp.Uncert. } \\ 1.0059 & 3.772 & 0.9898 & 0.9920 & 0.0060 \\ 1.0059 & 4.999 & 0.9945 & 0.9925 & 0.0050 \\ 1.0059 & 6.614 & 0.9830 & 0.9875 & 0.0058 \\ 1.0059 & 6.881 & 0.9761 & 0.9821 & 0.0054 \\ 1.0059 & 7.449 & 0.9680 & 0.9702 & 0.0070 \\ 1.0704 & 3.728 & 1.0125 & 1.0063 & 0.0070 \\ 1.0704 & 5.778 & 1.0103 & 1.0064 & 0.0080 \\ 1.0704 & 7.075 & 0.9964 & 0.9957 & 0.0061 \\ 1.1586 & 3.728 & 1.0358 & 1.0298 & 0.0060 \\ 1.1586 & 5.926 & 1.0412 & 1.0330 & 0.0051 \\ 1.1586 & 6.838 & 1.0311 & 1.0313 & 0.0032 \\ 1.1586 & 7.449 & 1.0240 & 1.0209 & 0.0051\end{array}$

\subsection{MKIA Lattice Experiment}

A set of criticality measurements was made using a lattice of actual $\mathrm{N}$ Reactor MKIA fuel elements (Brown et al. 1965). These results have the advantage that they are representative of actual $\mathrm{N}$ reactor fuel configurations, with fuel elements of metallic uranium with density close to $18.64 \mathrm{~g} / \mathrm{cm}^{3}$. However, experimental uncertainties were not reported either in the initial report or by wittekind (1992). For this reason, the original report was reviewed with the intent to determine the validity of the results and to obtain semiquantitative uncertainties.

The experiment consisted of three distinct types of measurements (exponential pile, neutron multiplication, and pulsed-neutron) and two fuel lattice configurations (MKIA outers and tube-in-tube). Several different lattices pitches were also included.

The primary results used by Wittekind for the MCNP validation tests were taken from the exponential measurements for the tube-in-tube geometries. Expressed as the number of MKIA fuel elements to reach $k_{\text {eff }}=1$, this gave three experimental values, $101.2,67.4$, and 90.3 corresponding to lattice pitches of $2.8 \mathrm{in.,} 3.1 \mathrm{in.}$, and $3.4 \mathrm{in}$. The corresponding metric values are $7.112 \mathrm{~cm}$, $7.874 \mathrm{~cm}$, and $8.636 \mathrm{~cm}$. These experimental values are shown on Figure 2 along 
WHC-SD-SNF-ANAL-013, Rev. 0

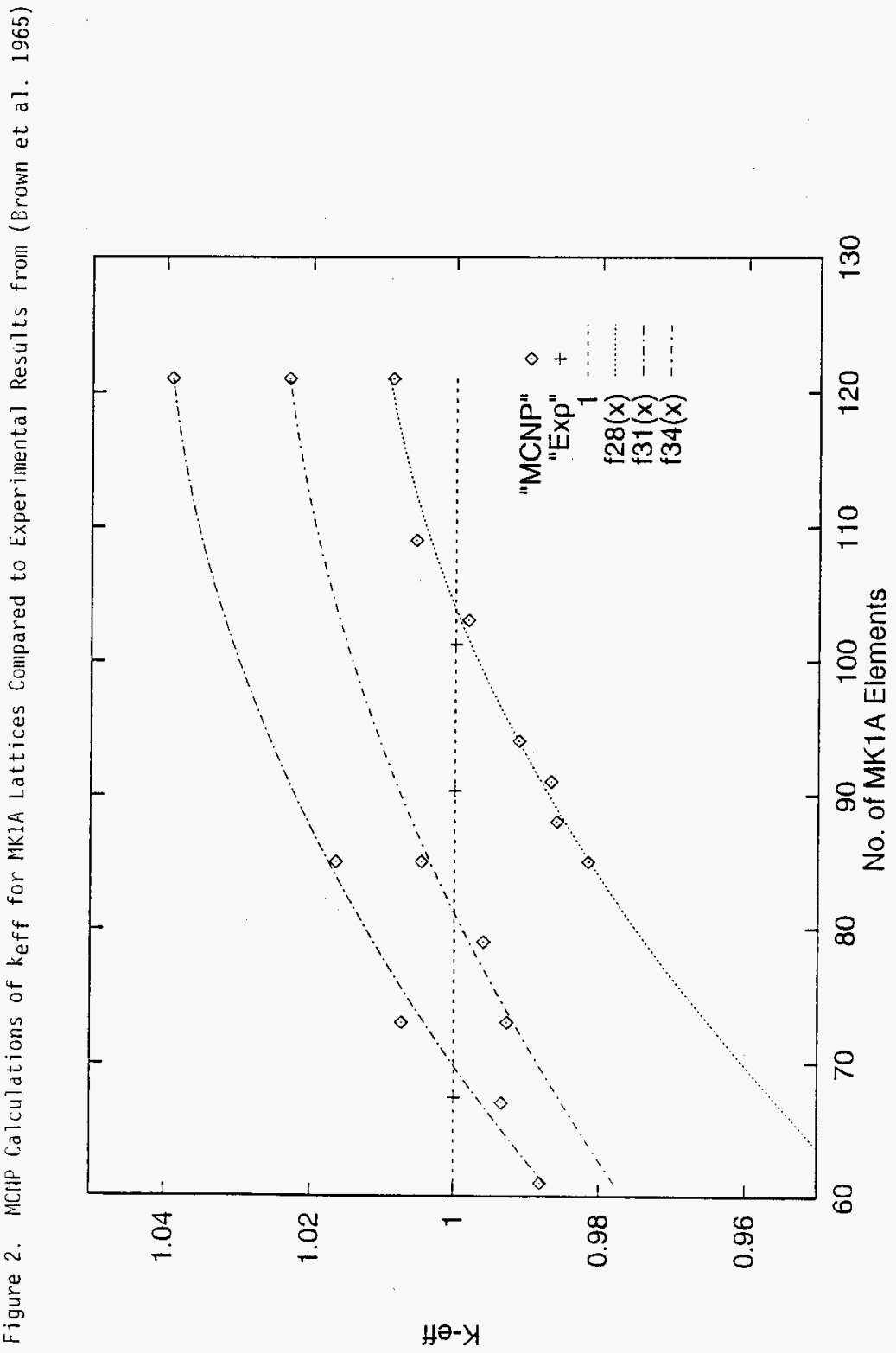


with the corresponding MCNP calculations made by Wittekind. The calculated values of $k_{\text {eff }}$ are taken directly from Table 6-5 in Wittekind (1992).

Representative MCNP statistical uncertainties are $2 \mathrm{mk}$. The $3.1 \mathrm{in}$. lattice is most reactive and is between the two other two lattice pitches.

To compare the experimental and calculated values, quadratic regression curves were fitted to the calculated points. As seen in Figure 2, the MCNP $k_{\text {eff }}$ values corresponding to the same number of MKIA elements are slightly below the measured values for the $2.8 \mathrm{in}$. and $3.1 \mathrm{in}$. pitches and high for the 3.4 in. result. Ratios of the MCNP-fitted curves to the experimental values were found for the three lattice pitches. These ratios are $0.9979,0.9968$, and 1.0077 for the lattice pitches $2.8 \mathrm{in.}, 3.1 \mathrm{in.,}$ and $3.4 \mathrm{in}$. respectively.

\section{Uncertainties}

Experimental uncertainties were not reported for the measured values. Nevertheless a review of the experimental report (Brown et a1. 1965) provides some useful information. The estimated number of critical tubes for the enriched outer tubes were determined separately by both neutron multiplication and by exponential pile measurements for two lattice pitches, 2.8 in. and 3.1 in. The exponential pile (or buckling) measurements are based on the falloff of the neutron flux as a function of $z$ while the neutron multiplication measurements represent an extrapolation of the inverse count-rate to zero. The two measurements differ by 1 tube for the $2.8 \mathrm{in}$. lattice and by 3.5 tubes for the $3.1 \mathrm{in.}$ lattice. Based on the given graphs, a qualitative estimate of the extrapolation error for the multiplication measurements is roughly three or four tubes (1-sigma), a result reasonably consistent with the separate agreement with the exponential measurements.

Neutron multiplication measurements were not reported for the tube-in-tube measurements used by Wittekind. However the experimental setup and measurements were the same as for the enriched outer tubes. Given the overall consistency of the results and giving consideration to the difficulties in assessing extrapolation errors, a relatively large value of \pm 5 tubes was chosen to reflect the uncertainty in the critical number of tubes.

The corresponding uncertainty in $k_{\text {eff }}$ can be obtained by reference to Figure 2. The three displayed curves have slopes close to 0.001 for points near the measurements. Thus an uncertainty of \pm 5 tubes corresponds to an uncertainty of \pm 0.005 in $k_{\text {eff }}$.

\section{Subcriticality of Low Enriched Systems}

It is worth noting that the small $\Delta \mathrm{k} / \Delta \mathrm{N}$ slope implies a small change in $\Delta \mathrm{k}$ for a fairly large change $\Delta \mathrm{N}$ in the number of MKIA tubes. For example, to move from a subcritical value of $k_{\text {eff }}=0.98$ to a value of 1.0 requires the addition of roughly 20 fuel elements. 


\subsection{Benchmark Experiment for 2.35\% Enriched Lattice}

A set of measurements not included in Wittekind's validation is documented for benchmark experiments performed at Pacific Northwest Laboratories critical mass laboratory and designated as LEU-COMP-THERM-001 (Briggs et al. 1992). Results are given for eight water-moderated $\mathrm{UO}_{2}$ (2.35\% enriched) lattices, mostly grouped in three clusters. The theoretical density of uranium oxide fuel, $\mathrm{UO}_{2}$ is $10.96 \mathrm{~g} / \mathrm{cm}^{3}$ which calculates to a maximum effective uranium density (taking into account the presence of $\mathrm{U}^{238} \mathrm{O}_{2}$ ) of $9.66 \mathrm{~g} / \mathrm{cm}^{3}$.

Although the enrichment is about twice that of the $N$ Reactor fuel, the benchmark report includes a very detailed analysis of the experimental uncertainties. The reported benchmark value for $k_{\text {eff }}$ is $0.9998 \pm 0.0031$. (The value less than one accounts for a small correction from acrylic lattice plates omitted from the model.) The experimental uncertainties are primarily due to lattice characteristics: enrichment, fuel diameter, and pitch.

The benchmark report also includes MCNP results with statistical errors for comparison $(\approx 1.6 \mathrm{mk})$. Resulting values are reproduced in Table 2 . Three cases for which MCNP input models were already constructed were recalculated

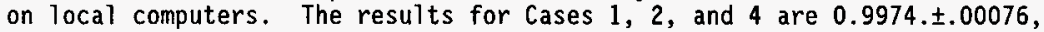
$0.9950 \pm .00089$, and $0.9964 \pm .00081$ respectively. The three recalculated values are biased low with an average bias of -3.5 mk which compares well with an average bias of -3.2 mk for the eight benchmark calculations.

Table 2. MCNP calculations for benchmark LEU-COMP-THERM-001 as reported in Briggs et al.(1992).

\begin{tabular}{||l|l|l|l||}
\hline $\begin{array}{l}\text { Case } \\
\text { Number }\end{array}$ & $\begin{array}{l}\text { Number of } \\
\text { Clusters }\end{array}$ & $\begin{array}{l}\text { Cluster Dimensions } \\
\text { (No. of rods, X } \times Y \text { ) }\end{array}$ & MCNP \\
\hline \hline 1 & 1 & $20 \times 18.08$ & $0.9987 \pm .0016$ \\
\hline 2 & 3 & $20 \times 17$ & $0.9977 \pm .0017$ \\
\hline 3 & 3 & $20 \times 16$ & $0.9956 \pm .0016$ \\
\hline 4 & 3 & $\begin{array}{l}20 \times 16 \text { (center) } \\
22 \times 16 \text { (two outer) }\end{array}$ & $0.9992 \pm .0014$ \\
\hline 5 & 3 & $20 \times 15$ & $0.9970 \pm .0016$ \\
\hline 6 & 3 & $\begin{array}{l}20 \times 15 \text { (center) } \\
24 \times 15 \text { (two outer) }\end{array}$ & $0.9955 \pm .0015$ \\
\hline 7 & 3 & $20 \times 14$ & $0.9968 \pm .0017$ \\
\hline 8 & 3 & $19 \times 16$ & $0.9921 \pm .0015$ \\
\hline
\end{tabular}




\subsection{STATISTICAL ANALYSIS}

The three sets of results are conveniently compared in Figure 3 where the ratios of the MCNP values to the corresponding measured values are shown. (The abscissa is an arbitrary index that delineates the distinct measurements.) The first 12 points represent the homogeneous $\mathrm{UO}_{3}-\mathrm{H}_{2} \mathrm{O}$ solution results; the second set of 3 points represents the metallic uranium MKIA lattice measurements; and the final set of 8 points represents the $2.35 \%$ enriched uranium oxide benchmark values. (Note that for values this close to unity, the difference between the calculation to measurement ratio, $C / E$, and one is nearly equivalent to the absolute difference, $C / E-1 \approx C-E$.)

These data can now be used to determine a calculational bias, b, defined by

$$
k_{\text {calc }}=k_{\text {eff }}+b
$$

where $k_{\text {calc }}$ represents the calculated estimate of $k_{\text {eff }}$.

Following standard practice (see Macklin and Miller (1991) for example), a lower tolerance limit $b_{L}$ is established such that one is $95 \%$ confident that $95 \%$ of the population is above the limit. The non-central t-distribution gives a prescription (Resnikoff and Lieberman 1956) for this limit:

$$
b_{L}=b_{a v e}-K_{b} s_{b}
$$

where $b_{\text {ave }}$ is the mean value and $s_{b}$ is the corresponding sample variance. The multiplier $K_{b}$ may be found from statistical tables of the non-central $t-$ distribution and depends on the number of degrees of freedom (DOF) for the supporting measurements.

\section{Application}

The application of these statistical rules requires some judgement since there is not a unique way to analyze the data. One possibility is to pool the data, treating each measurement as an independent value and using the sample variance as an estimate of the uncertainty. There are several concerns with this approach. First there is no assurance, at least for the present study, that the data are independent. Secondly, it ignores useful information contained in the estimated uncertainties. For example, one subset of the data could have fewer values that would reduced its weight even though it had smaller prior uncertainties. The relation of a given set of measurements to the desired conditions (such as similar enrichments or uranium density) is also ignored. Finally, the variations in the $C / E$ values arises from a variety of separate sources that may not be adequately sampled. In statistical terms, the number of degrees of freedom associated with the measurements is difficult to determine. Here the three separate sets of measurements, which represent distinct experimental conditions, are first considered individually. They are 
WHC-SD-SNF-ANAL-013, Rev. 0

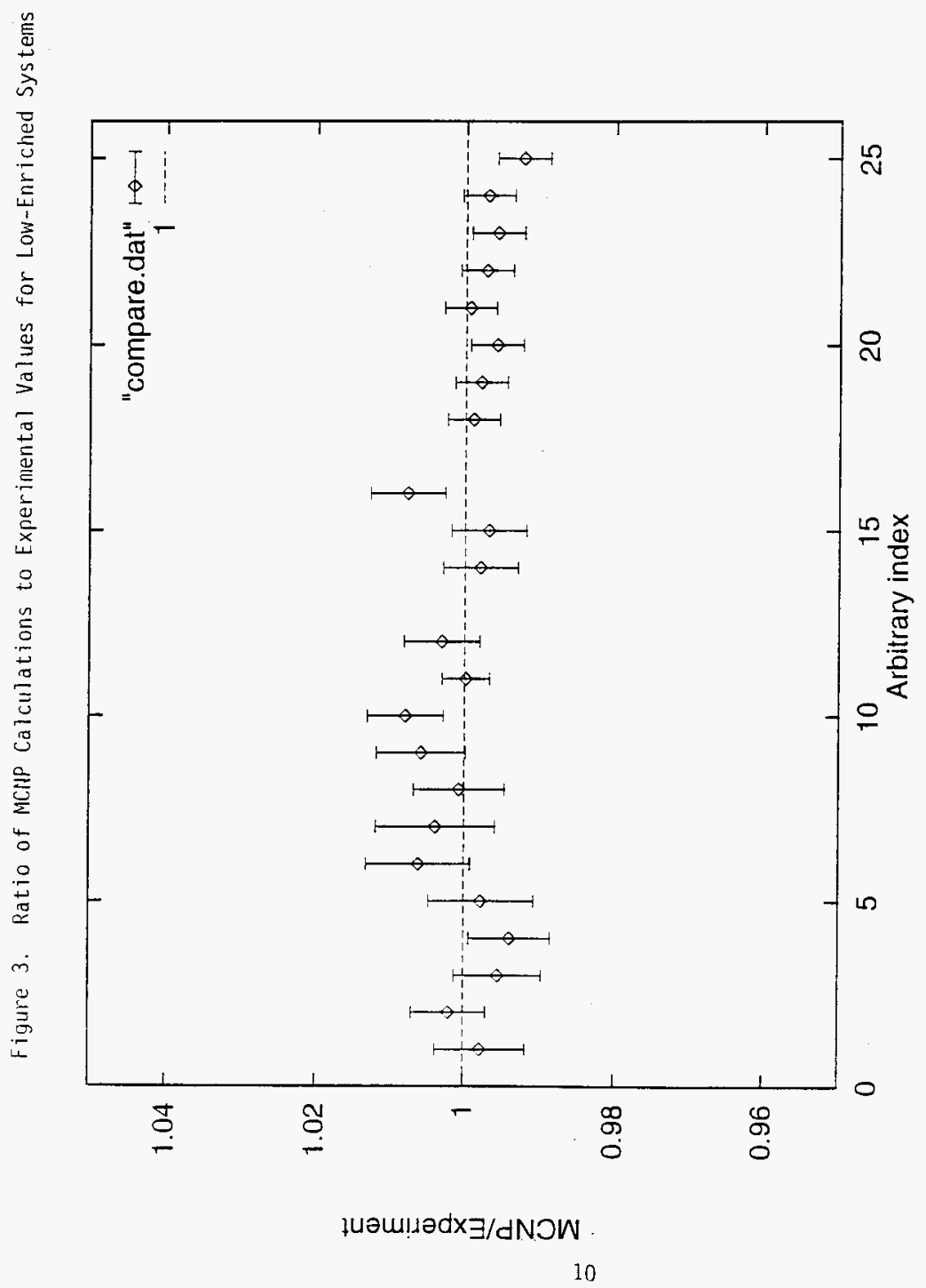


then considered jointly with due consideration of their overall consistency and relevance. The results are summarized in Table 3 below which shows the average bias, $b_{\text {gve, }}$ and the associated sample variance (expressed as a standard deviation, $s_{b}$ ) for each of the three individual data sets and for the pooled total set of data. The average assigned experimental uncertainty, omave, is shown for comparison.

Table 3. Statistical MCNP Bias Results for Three Experiments and the Pooled Data.

\begin{tabular}{|l|l|l|l|l|l||}
\hline Description & $\mathrm{n}$ & $\mathrm{b}_{\text {ava }}, \mathrm{mk}$ & $\mathrm{s}_{\mathrm{h}}, \mathrm{mk}$ & $\sigma_{\text {m-ave }}, \mathrm{mk}$ & $\mathrm{sb} / \sigma_{\text {m-ave }}$ \\
\hline U0 $0_{3}$-H20 soln. & 12 & 1.2 & 4.4 & 5.8 & 0.76 \\
\hline MKIA elements & 3 & 0.8 & 6.0 & 5.0 & 1.20 \\
\hline Benchmark exp. & 8 & -3.2 & 2.2 & 3.5 & 0.64 \\
\hline Pooled data & 23 & -0.4 & 3.8 & 4.9 & 0.78 \\
\hline
\end{tabular}

The MCNP calculations are biased slightly high for the first two sets of experimental values but well within the sample standard deviation. The benchmark calculations for the $2.35 \%$ enriched oxide fuel are biased low (see also Figure 2) but are within the assigned average experimental uncertainty. The bias is somewhat larger than the sample standard deviation, however this value could easily be low if the values are correlated as appears to be the case from Figure 2 .

As shown by the last column in Table 3, the uncertainties as determined from the sample variance are in reasonable agreement with the prior assigned experimental uncertainties. Since the sample variance is distributed as chisquare, this comparison could be made more quantitative; however, the difficulty in determining the associated degrees of freedom reduces the value of doing so.

Based on the results in Table 3 , the pooled bias of $b_{\text {ave }}=-0.4 \mathrm{mk}$ was chosen for final result. This choice includes the lower values of the benchmark data giving a conservative result. A standard deviation of $s_{b}=5.0 \mathrm{mk}$ was chosen in favor of the somewhat lower value of $3.8 \mathrm{mk}$ associated with pooled sample variance. The latter value assumes that all the data points are independent, while the larger value is generally consistent with the results in Table 3 .

Finally, a value of the multiplier, $K_{b}$ is detemined. A precise value for $K_{b}$ can only be determined for a known number of degrees-of-freedom. Nevertheless for a 95/95 tolerance limit, standard non-central t-distribution tables show that $K_{b}$ ranges from 2.4 to 1.9 as the DOF range from 20-100. Given that a somewhat conservative value was already chosen for $s_{b}$, a conventional and rounded value of $K_{b}=2.0$ is a good practical choice. 
The final result for the lower tolerance limit of the bias (calculated to two significant figures and rounded up to be conservative) is

$$
\begin{aligned}
\mathrm{b}_{\mathrm{L}} & =-0.4-(2)(5.0) \\
& =-11 \mathrm{mk}
\end{aligned}
$$

Therefore, $+11 \mathrm{mk}$ should be added to MCNP criticality computed results prior to checking for other prescribed limits.

To account for Monte Carlo statistical uncertainties, an additional value $1.645 \sigma_{c}$ is added in quadrature to the bias uncertainty. This means that the MCNP Monte Carlo statistical uncertainties are not correlated to the uncertainty in the bias when compared to experiment, a reasonable assumption The value of 1.645 is the number of standard deviations in the standard normal distribution required to yield $95 \%$ confidence in the calculation. For example, a value of $\sigma_{c}=2.0 \mathrm{mk}$ would yield a combined limit of:

$$
-0.4-\left[10^{2}+(1.645 \times 2)^{2}\right]^{1 / 2}=-10.9 \mathrm{mk} \text {. }
$$

\subsection{RESULTS AND RECOMMENDATIONS}

The results are summarized by

$$
k_{\text {calc }}+0.0004+\sqrt{0.010^{2}+\left(1.645 \sigma_{\text {calc }}\right)^{2}}<k_{\text {limit }}
$$

where $k_{\text {calc }}$ and $\sigma_{\text {calc }}$ represent the calculated value for $k_{\text {eff }}$ and its standard deviation respectively. The limit, $k_{\text {lnit, }}$ is an established limiting value. The multiplier of 1.645 ensures that $95 \%$ of the Monte Carlo population is bounded by the limit and assumes that there is no uncertainty in the standard deviation, $\sigma_{\text {calc. }}$. It can be obtained from tables of the normal distribution; alternately it also corresponds to the non-central t-distribution multiplier for an infinite number of degrees of freedom.

A value of $\sigma_{\text {calc }}$ that is larger than that accepted by almost all criticality calculations done by specialists using MCNP is $0.004 \mathrm{k}$. For this value, the bias limit would be:

$$
k_{c a I c}+0.0004+\sqrt{0.010^{2}+(1.645 * 0.004)^{2}}<k_{\text {limit }}
$$




$$
k_{c a l c}<k_{1 \text { imit }}-0.013 k
$$

so

$$
k_{\text {calc }}+0.013 k<k_{1 \text { imit }}
$$

All resulting values are rounded up to be conservative.

Using the above calculated bias value means that the $\mathbf{k}_{\text {calc }}$ computed from a new MCNP run would have to be below $k_{\text {limit }}-0.013 k$ in meeting the allowable limit on $k_{\text {eff }}$. For a $k_{\text {limjt }}$ of $0.95, k_{\text {calc }}$ would have to be less than 0.937 to be within acceptable limits. If this particular value is used for the acceptable limit, the $\sigma_{\text {calc }}$ must be less than 0.004 for each calculation. Table 4. gives other calculated biases for given values of $\sigma_{\text {calc }}$ that could be used to designate an acceptable 1 imit on the $k_{\text {eff }}$ computed by ${ }^{c a c} \mathrm{NP}$.

Table 4. Biases calculated from given $\sigma_{\text {calc }}$

\begin{tabular}{|c|c|}
\hline $\begin{array}{c}\sigma_{c \mathrm{~B} j \mathrm{c}} \\
(\mathrm{k})\end{array}$ & bias $\operatorname{limit}_{(k)}\left(b_{L}\right)$ \\
\hline 0.001 & -0.011 \\
\hline 0.002 & -0.011 \\
\hline 0.003 & -0.012 \\
\hline 0.004 & -0.013 \\
\hline 0.005 & -0.013 \\
\hline 0.006 & -0.015 \\
\hline 0.007 & -0.016 \\
\hline
\end{tabular}

bias

For most situations, the dominant correction is the $10 \mathrm{mk}$ correction arising from the uncertainty in the bias analysis, scatter in the calculation of $k_{\text {eff }}$ for the benchmark cases. The bias of $-0.4 \mathrm{mk}$ is not significantly different from zero. 
The widespread use of MCNP in a variety of situations adds a measure of confidence to these results significantly beyond the quantitative aspects reported here.

Additional work that could be done within the context of the present study includes surveying additional experimental results and to independently recreate and apply the MCNP 2.35\%-enriched oxide fuel benchmark models. However, this would represent a significant increase in work scope.

A theoretical assessment of the relevance of the results for the higherenriched experiments could also be carried out.

\subsection{PEER REVIEW}

This document was peer reviewed for three aspects; genera1, MCNP technics (Carter 1996) and statistical validity (Kline 1996).

\section{1 GENERAL PEER REVIEW}

The general review was done for technical content and adequacy by Warren $D$. Wittekind of Criticality and Shielding. His comments follow:

A bias calculation should be appropriate for the application intended.

The bias calculation performed in 1992 (Wittekind 1992) was for solid metallic uranium in a uranium bearing solution. This study broadens the application to all low enriched uranium systems by including a 2.35 wt\% uranium oxide fuel case which has a uranium density midway between homogeneous solutions and metallic uranium slugs. The bias limitation is the precision of the historical criticality experiments and not the precision of present day computer calculations. The emphasis on criticality experiments has diminished in recent years while progress in computer performance, especially speed, which reduces the Monte Carlo statistical uncertainty, has progressed rapidly.

There are assumptions in these statistical bias calculations which reflect the author's values of how much to weight the various benchmark experimental classes. The assumption which led to $b_{L}=-0.4 \mathrm{mK}$ and with the $95 \%$ confidence interval (single sided) of $10 \mathrm{mK}$ are conservative, and reasonable and defensible. 


\subsection{MCNP TECHNICS PEER REVIEW}

This document was reviewed by Lee L. Carter of the Criticality and Shielding Group for proper use of the MCNP computer code. His comments follow:

I have reviewed this report and am in agreement with the approach and recommendation obtained for the bias and the uncertainty in the bias; i.e., as given by the inequality at the beginning of section 4.0. This EDT does not mention that the MCNP calculations were made using ENDF/B-V cross sections at 300 degrees $K$. This is important since the validation is specifically for those cross sections as utilized by MCNP.

\subsection{STATISTICAL VALIDITY PEER REVIEW}

This document was reviewed by Niall W. Kline of the Information and Scientific Systems Group, Lockheed Mart in Services, Inc. for proper statistical treatment of the data. His comments follow:

\section{Introduction}

Estimation of calculational bias with the MCNP code proceeds by collecting a sample of bias realizations. Each bias realization, $b$, is determined by

$$
b=k_{\text {calc }}-k_{\text {eff }} \text {, }
$$

where $k_{\text {eff }}$ is a measured value from a physical experiment and $k_{\text {calc }}$ is the analagous value determined from simulation of the physical experiment with the MCNP code. The intent is to obtain a sample from which to estimate the bias b that is inherent in using the MCNP code.

The sample used for this purpose in Section 3 is constructed of three subsamples. Each subsample is a set of realizations of $b$ that is determined from a set of related physical experiments. Issues regarding independence, sufficiency and convergence in relation to the sample and subsamples are raised in discussion of statistical estimates in Section 3. The purpose here is to provide some input to the resolution of those issues.

\section{Sample Independence}

Ideally the full sample should be a random sample; i.e., the realizations should be independent and identically distributed. Independence means that the value of any realization of $b$ does not depend on the value of any other realization of $b$. The measurements of $k_{\text {eff }}$ taken from the physical experiments are related in that the experiments are related and the values of $k_{\text {calc }}$ determined from simulations of the experiments are similarly related, but 
there is no correlation reported with the data and hence for the present purposes the realizations of bias are assumed to be independent. Under the assumption of independence, the number of degrees of freedom is equal to the sample size.

\section{Sample Homogeneity}

The realizations of bias should also be identically distributed, meaning that all of the realizations are from one homogeneous population. Display of the full sample in Figure 3 appears to suggest the possibility of subpopulations. Letting $b_{x}$ denote a realization of bias from the U03-H2O solution data $\left(n_{x}=12\right)$ and $b_{y}$ denote a realization from the benchmark experiment data $\left(n_{y}=8\right)$, the $b_{x}$ sample mean and sample standard deviation are $\mu_{x}=0.001225$ and $S_{x}=0.00446$ and the $b_{y}$ sample mean and sample standard deviation are $\mu_{y}=-0.003225$ and $S_{y}=0.00223$ (cf. Table 3). Note that $\mu_{y}$ is in the interval from $\mu_{x}$ to $\mu_{x}-S_{x}$, but $\mu_{x}$ is not in the interval from $\mu_{y}$ to $\mu_{y}+S_{y}$.

Homogeneity has been formalized as a null hypothesis $\left(H_{0}: F_{x}=F_{y}\right.$, where $F_{x}$ and $F_{y}$ denote the distribution functions of the $b_{x}$ and $b_{y}$ subsamples respectively), and tested with both the Runs test and the Rank-Sum test. Details of the Runs and Rank-Sum tests can be found in most texts on mathematical statistics. Using small Type I error, $0.01=\operatorname{Pr}($ Type I error) = the probability of rejecting the null hypothesis when it is true, then both the Runs test and the Rank-Sum test fail to reject the null hypothesis. This supports the homogeneity supposition and use of the "pooled" sample.

\section{Estimator}

The estimator of a lower bound on bias is taken to be

$$
b_{L}=b_{a v e}-K_{b} S_{b} \text {, }
$$

where $b_{\text {ave }}$ is the sample mean of the pooled sample $(n=23)$,

$S_{b}$ is the sample standard deviation of the pooled sample, and $K_{b}$ is the $95^{\text {th }}$ percentile from the non-central $t$ distribution.

Based on work by Dyer et a 1 (1991), $b_{L}$ is a 1ower 1 imit on a $95 \%$ single-sided, uniform width, closed-interval, lower tolerance band (LTB). In other terms, at least $95 \%$ of the biases realized with the MCNP code are expected to be greater than $b_{L}$, with $95 \%$ confidence.

\section{Sufficiency}

Broadly, an estimator is defined to be statistically sufficient if it preserves the information contained in the sample data. While the estimator 


\section{WHC-SD-SNF-ANAL-013 Rev. 0}

$b_{\text {b }}$ isn't necessarily insufficient, the estimator is supplemented hueristically to account for apparent (unquantified) experimental variation and Monte Carlo statistical uncertainty. The final form shown in Section 4 is more conservative; i.e., the final lower 1 imit includes at 1 east $95 \%$ of the biases realized with the MCNP code.

\section{Convergence}

Although the full sample size, $n=23$, is not small, neither is it a large sample. Investigation of adequacy of the sample in terms of both size and variation (degrees of freedom) is beyond the scope of this initial review effort.

\section{Conclusions}

Construction of a reasonable initial sample and estimation of a lower limit on at least $95 \%$ of the biases that are expected to be realized in use of the MCNP code has been undertaken with due consideration to concerns for stochastic independence of the sample and statistical sufficiency of the estimator. As part of this review investigation it has also been determined that the initial sample can satisfy a condition of homogeneity. Supplementation of the sample to provide indication of convergence of sample mean and variance estimates would be a useful extension of the present work. 


\subsection{REFERENCES}

Briggs, J. B., et al., 1992, International Handbook of Evaluated Criticality Safety Benchmark Experiments, Volume IV, Low Enriched Uranium Systems, NEA/NSC/DOC(95)03/IV, Nuclear Energy Agency, Organization for Economic Cooperation and Development OECD, Paris.

Brown, C. L., R. C., Lloyd, S. R. Bierman, and E. D. Clayton, 1965, Exponential Experiments and Neutron Multiplication Measurements with 1.25 wt\% Enriched $\mathrm{N}$-Reactor Fuel Elements in Light Water, BNWL-52, Battelle Northwest Laboratory, Richland, Washington.

Carter, L. L., 1991, Certification of MCNP Version $3 B$ for the Hanford Cray, WHC-SD-MP-SWD-30001, Rev 3, Westinghouse Hanford Company, Richland, Washington.

Macklin, L. L., and E. M. Miller, 1991, MONK6A Pu Validation, WHC-SD-SQA-CSWD20015, Rev 0, Westinghouse Hanford Company, Richland, Washington.

Neeley, V. I. and H. E. Handler, 1961, Measurement of Multiplication Constant for Slightly Enriched Homogeneous $\mathrm{UO}_{3}$-Water Mixtures and Minimum Enrichment for Criticality, HW-70310, General Electric, Richland, Washington.

Resnikoff, G. J., and Gerald J. Lieberman, 1957, Tables of the Non-Central t-Distribution, Stanford University Press, Stanford, California.

WIMS, 1992, WIMS6-WIMSE, A Scheme for Neutronics Calculations User Manual, AEEW-R2442, Winfrith Technology Centre, Dorchester, Dorset, England.

Wittekind, W.D., 1992, K Basin Criticality Evaluation for Irradiated Fuel Canisters in Sludge, WHC-SD-NR-CSER-001, Westinghouse Hanford Company, Richland, Washington.

Carter, L.L., 1996, Electronic mail to the author, October 4

Kline, N.W., 1996, Review of Estimation of Calculational Bias with the MCNP Code Lockheed Martin Services, Inc., Richland, Washington

Dyer, H.R., W.C. Jordan and V.R. Cain, 1991, "A Technique for Code Validation for Criticality Safety Calculations", presented at the 1991 Annual Meeting of the American Nuclear Society 


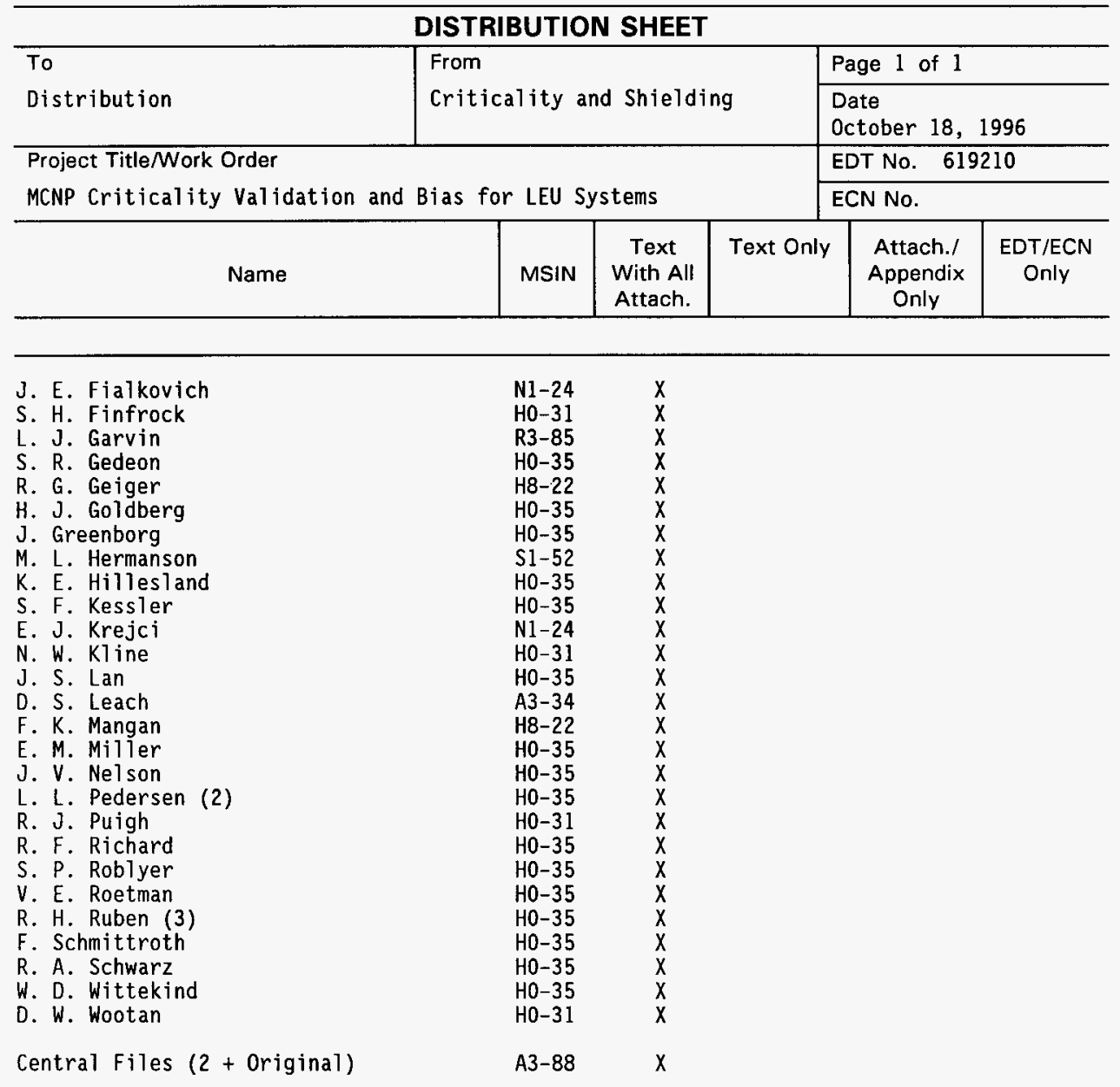

